\title{
Protocol
}

\section{Studies of Limb Regeneration in Larval Xenopus}

\author{
Anthony L. Mescher ${ }^{1,2,3}$ and Anton W. Neff 1,2 \\ ${ }^{1}$ Center for Developmental and Regenerative Biology, Indiana University, Bloomington, Indiana 47405; \\ ${ }^{2}$ Department f Anatomy and Cell Biology, Indiana University School of Medicine at Bloomington, Bloomington, \\ Indiana 47405
}

\begin{abstract}
A basic protocol is given for animal maintenance and surgery in studies of hindlimb regeneration in larval Xenopus laevis. Unlike urodele limbs, those of larval frogs typically show much more variation in the extent of regeneration after amputation. Such variation can be reduced by optimizing the conditions of larval maintenance to regulate the rates of growth and development, by selecting only larvae with normal rates of growth and morphological development for experimental use, and by attention to precision and consistency in the proximo-distal level of surgical amputation.
\end{abstract}

MATERIALS

It is essential that you consult the appropriate Material Safety Data Sheets and your institution's Environmental Health and Safety Office for proper handling of equipment and hazardous materials used in this protocol.

RECIPES: Please see the end of this protocol for recipes indicated by $<R>$. Additional recipes can be found online at http://cshprotocols.cshlp.org/site/recipes.

\section{Reagents}

\section{Anesthetic solution}

Dissolve $0.1 \mathrm{~g}$ of benzocaine (ethyl 4-aminobenzoate; Sigma-Aldrich) or MS222 (ethyl 3-aminobenzoate methanesulfonate; Sigma-Aldrich) in $10 \mathrm{~mL}$ of absolute ethanol. Dilute to $1 \mathrm{~L}$ with artificial pond water. If necessary, buffer to $\mathrm{pH}$ 7. Prepare fresh weekly, or as needed.

Artificial pond water $<\mathrm{R}>$

Fixative (e.g., $4 \%$ formalin or 100\% methanol) (optional; see Step 17)

Tadpole Powder (Xenopus express)

Xenopus embryos

Obtain embryos as described by Sive et al. (2000).

Equipment

Aquarium aerator

Containers for larvae, glass or plastic, 3-L

Culture plate, $10-\mathrm{cm}$ diameter

Gauze

Spring scissors, 10- to 15-mm cutting edge, Castroviejo or Noyes (Roboz or Fine Science Tools)

Stereomicroscope

${ }^{3}$ Correspondence: mescher@indiana.edu

From the Xenopus collection, edited by Hazel L. Sive.

(c) 2019 Cold Spring Harbor Laboratory Press

Advanced Online Article. Cite this protocol as Cold Spring Harb Protoc; doi:10.1101/pdb.prot100990

This is the author's manuscript of the article published in final edited form as: 
A.L. Mescher and A.W. Neff

\section{METHOD}

\section{Husbandry of Xenopus laevis Larvae}

1. At approximately developmental Stage 45 (as defined by Nieuwkoop and Faber 1994), separate the larvae into containers containing $2.5 \mathrm{~L}$ artificial pond water, at a population density not exceeding 1 larva per $500 \mathrm{~mL}$.

2. Maintain larvae at $23 \pm 2^{\circ} \mathrm{C}$ in natural light or a $12 / 12$ dark/light cycle. Feed once a day with tadpole powder in an amount that allows all to be eaten before the next feeding.

3. Change artificial pond water daily or every second day:

i. Remove larvae carefully with a soft net.

ii. Wipe biofilm from the container.

iii. Add fresh pond water.

Ensure that the fresh water is at the same temperature as that removed.

iv. Replace the larvae.

4. Examine the larvae daily. Eliminate those with abnormalities or significantly reduced rates of growth or external development.

\section{Anesthesia and Hindlimb Amputation of Larvae}

Excellent fate maps of developing Xenopus laevis hindlimbs were published by Tschumi (1957) and recently reprinted by Keenan and Beck (2016).

5. Select an appropriate number of larvae for the specific experiment (10-15 animals is recommended), ensuring that all are at the desired developmental stage.

Under ideal environmental conditions (Nieuwkoop and Faber 1994), hindlimb buds appear at Stage 46 and become longer than they are broad at Stage 50, 15 d after fertilization.

6. Place 1-2 larvae in a small bowl or $10-\mathrm{cm}$ tissue culture plate containing $40-50 \mathrm{~mL}$ of freshly prepared anesthetic solution.

7. Place an immobilized larva on gauze moistened with artificial pond water. Position the larva on its side to allow a good view of the developing hindlimb when placed on the stage of the stereomicroscope.

8. Blot excess water from the exposed larval flank and hindlimb. Focus the microscope on the latter.

9. Using spring scissors, amputate the hindlimb at a $90^{\circ}$ angle to the proximal-distal axis, taking care to do so at the precise proximal-distal level desired, and at the exact same level in each successive limb.

See Troubleshooting.

10. If bilateral amputation is desired, use a plastic spoon to carefully turn the larva over. Amputate the other hindlimb as above.

11. Place each amputated larva in $\sim 1 \mathrm{~L}$ of artificial pond water aerated continuously with an aquarium aerator until fully awake and swimming normally.

12. Repeat Steps 6-11 until all the animals have been processed.

13. When all experimental larvae are active and swimming normally, place in containers of artificial pond water. Maintain husbandry at a density similar to that before surgery.

14. Visually monitor hindlimb regeneration and animal development daily. Eliminate larvae that develop abnormalities or show significantly reduced rates of overall growth or external development.

See Discussion for the importance of this procedural step. 
15. At the desired time point or regenerative stage postamputation, place the larvae individually again in the anesthetic. Use spring scissors to remove the regenerating limbs at the pelvis (or other level, as desired).

16. Immediately place each limb in an appropriate fixative or extraction buffer as required for histological or molecular analysis, respectively.

17. After removal of the experimental tissues, euthanize each larva by decapitation or by reimmersion in anesthetic, followed by placement in $4 \%$ formalin or $100 \%$ methanol.

\section{TROUBLESHOOTING}

Problem (Step 9): In hindlimbs at Stage 57 or later, the cut end(s) of skeletal elements can protrude slightly after amputation.

Solution: Cut the protruding skeletal tissue again flush with the soft tissues of the limb stump.

\section{DISCUSSION}

Anuran tadpoles and various urodele species such as newts (Notophthalmus viridescens, Pleurodeles waltl, Cynops pyrrhogaster, and Cynops orientalis) or axolotls (Ambystoma mexicanum) are the only tetrapod research models capable of complete limb regeneration after amputation (Song et al. 2010). Regeneration in both anurans and urodeles appears similar in terms of the tissue interactions required for limb regrowth and development, but the process in anuran larvae differs from that of urodeles in at least two respects. Importantly, in anurans the capacity to successfully pattern a new limb declines during larval development and is gradually lost, first in proximal portions of the limb and then in progressively more distal levels, during the onset of metamorphosis (Schotté and Harland 1943). The gradual decline of regenerative ability in developing Xenopus laevis hindlimbs—showed by both Komala (1957) and Dent (1962) — is indicated by the reduced number of articulated digits, with the first digits lost being those formed last during larval development (Muneoka et al. 1986). The developmental decline of regenerative capacity allows important processes that follow amputation, such as localized gene expression changes (Grow et al. 2006) and inflammation (Mescher et al. 2013), to be compared at stages when regeneration is expected to be complete or incomplete (King et al. 2012).

The second difference between anuran and urodele limb regeneration is that although patterning in the latter is almost always perfect (or nearly so), morphogenesis in regenerating hindlimbs of anuran tadpoles is often quite variable even in limbs amputated well before metamorphosis, which in Xenopus occurs during Stages 57-66 (Nieuwkoop and Faber 1994). A summary figure of Dent (1962) suggests that limbs amputated through the presumptive region of the distal thigh at Stages 53 and 55 are expected to regenerate four- and three-digit limbs, respectively. However his quantitative data show that more than one-third of the hindlimbs amputated at those stages failed to achieve those results. Similar variability in digit patterning with this system has also been reported by other investigators (e.g., Shimizu-Nishikawa et al. 2003; Slack et al. 2004; King et al. 2012).

The variability of regeneration in Xenopus hindlimbs was investigated by Nye and Cameron (2005) and discussed in a review by Beck et al. (2009). Nye and Cameron (2005) showed that such variation is reduced by attention to precision and consistency in the amputation plane, and by ensuring normal larval growth and development. They found that even under "optimal" growth conditions laboratoryraised Xenopus larvae go through metamorphosis $\sim 1$ wk later than the larvae described by Nieuwkoop and Faber (1994), which were collected in nature and "...had developed under the most natural conditions [their italics]... the water was green with algae...” (Nieuwkoop and Faber 1994). Even with well-fed sibling larvae raised at the low population density used in this protocol, growth and development often slow and can eventually stop in a significant percentage of animals. When hindlimbs 
of these abnormal larvae are amputated, regeneration occurs very slowly and with poor patterning compared to that in normally developing, younger larvae amputated at the same NieuwkoopFaber stage (Nye and Cameron 2005; Beck et al. 2009). Nye and Cameron (2005) recommended that each laboratory establish that the growth curve of their tadpoles approximates that of Nieuwkoop and Faber (1994) and that slow-growing or developmentally abnormal tadpoles be eliminated from experimental analyses of limb regeneration to avoid excessively variable results.

As discussed by Mescher (2017), it is of interest that maturation of the immune system continues in Xenopus larvae whose external morphological development has slowed (Ruben et al. 1972; RollinsSmith et al. 1997). Those studies showed that slow-growing larvae at an early morphological stage, when complete hindlimb regeneration is expected, can have immunological capabilities typical of later stages, when regeneration is normally defective. We have reported initial studies on the localization of antigen-presenting cells in the skin of developing Xenopus hindlimbs (Mescher et al. 2007). The data are consistent with the view that this maturation of cutaneous immunity could elicit qualitatively different inflammatory responses to amputation that lead to the developmental decline of regenerative capacity, similar to the process by which a tendency for postinjury scarring increases during skin maturation in other vertebrates.

\section{RECIPE}

\section{Artificial Pond Water}

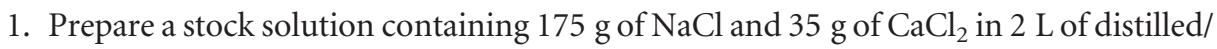
deionized water.

2. Prepare a second stock solution containing $5 \mathrm{~g}$ of $\mathrm{NaHCO}_{3}$ in $2 \mathrm{~L}$ of distilled/deionized water.

3. To $70 \mathrm{~L}$ (44 gal) of distilled/deionized water in an HDPE plastic barrel on casters (e.g., Rubbermaid Commercial Products) add $280 \mathrm{~mL}$ of each stock solution and $25 \mathrm{~mL}$ of NovAqua water conditioner (Kordon).

This "water conditioner" buffers the $\mathrm{pH}$, adds other electrolytes, and removes chlorine, chloramine, and heavy metals.

4. Keep the barrel lidded and the contents aerated.

Prepare fresh every $3-4 \mathrm{~d}$.

\section{REFERENCES}

Beck CW, Izpisúa Belmonte JC, Christen B. 2009. Beyond early development: Xenopus as an emerging model for the study of regenerative mechanisms. Dev Dyn 238: 1226-1248.

Dent JN. 1962. Limb regeneration in larvae and metamorphosing individuals of the South African clawed toad. J Morph 110: 61-77.

Grow M, Neff AW, Mescher AL, King MW. 2006. Global analysis of gene expression in Xenopus hindlimbs during stage-dependent complete and incomplete regeneration. Dev Dyn 235: 2667-2685.

Keenan SR, Beck CW. 2016. Xenopus limb bud morphogenesis. Dev Dyn 245: 233-243.

King MW, Neff AW, Mescher AL. 2012. The developing Xenopus limb as a model for studies on the balance between inflammation and regeneration. Anat Rec 295: 1552-1561.

Komala Z. 1957. Comparative investigations on the course of ontogenesis and regeneration of the limbs in Xenopus laevis tadpoles in various stages of development. Folia Biol 5: 1-51. [in Polish].

Mescher AL. 2017. Macrophages and fibroblasts during inflammation and tissue repair in models of organ regeneration. Regeneration 4: $39-53$.
Mescher AL, Wolf WL, Moseman EA, Hartman B, Harrison C, Nguyen E, Neff AW. 2007. Cells of cutaneous immunity in Xenopus: Studies during larval development and limb regeneration. Dev Comp Immunol 31: 383-393.

Mescher AL, Neff AW, King MW. 2013. Changes in the inflammatory response to injury and its resolution during the loss of regenerative capacity in developing Xenopus limbs. PLoS One 8: e80477.

Muneoka K, Holler-Dinsmore G, Bryant SV. 1986. Intrinsic control of regenerative loss in Xenopus laevis limbs. J Exp Zool 240: 47-54.

Nieuwkoop PD, Faber J (eds.). 1994. Normal table of Xenopus laevis (Daudin): A systematical \& chronological survey of the development from the fertilized egg till the end of metamorphosis. Garland Publishing, New York.

Nye HLD, Cameron JA. 2005. Strategies to reduce variation in Xenopus regeneration studies. Dev Dyn 234: 151-158.

Rollins-Smith LA, Flajnik MF, Blair PJ, Davis AT, Green WF. 1997. Involvement of thyroid hormones in the expression of MHC class I antigens during ontogeny in Xenopus. Dev Immunol 5: 133-144.

Ruben LN, Stevens JM, Kidder GM. 1972. Suppression of the allograft response by implants of mature lymphoid tissues in larval Xenopus laevis. J Morph 138: 457-465. 
Schotté OE, Harland M. 1943. Amputation level and regeneration in limbs of late Rana clamitans tadpoles. J Morphol 73: 329-362.

Shimizu-Nishikawa K, Takahashi J, Nishikawa A. 2003. Intercalary and supernumerary regeneration in the limbs of the frog, Xenopus laevis. Dev Dyn 227: 563-572.

Sive HL, Grainger RM, Harland RM. 2000. Early development of Xenopus laevis: A laboratory manual. Cold Spring Harbor Laboratory Press, Cold Spring Harbor, NY.
Slack JMW, Beck CW, Gargioli C, Christen B. 2004. Cellular and molecular mechanisms of regeneration in Xenopus. Philos Trans R Soc Lond B Biol Sci 359: 745-751.

Song F, Li B, Stocum DL. 2010. Amphibians are research models for regenerative medicine. Organogenesis 6: 141-150.

Tschumi PA. 1957. The growth of the hindlimb bud of Xenopus laevis and its dependence upon the epidermis. J Anat 91: 149-173. 


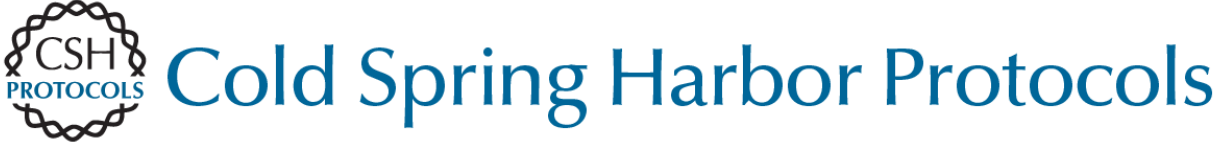

\section{Studies of Limb Regeneration in Larval Xenopus}

Anthony L. Mescher and Anton W. Neff

Cold Spring Harb Protoc; doi: 10.1101/pdb.prot100990; published online June 12, 2018

\begin{tabular}{rc}
$\begin{array}{r}\text { Email Alerting } \\
\text { Service }\end{array}$ & Receive free email alerts when new articles cite this article - click here. \\
\hline $\begin{array}{c}\text { Subject } \\
\text { Categories }\end{array}$ & $\begin{array}{c}\text { Browse articles on similar topics from Cold Spring Harbor Protocols. } \\
\text { Developmental Biology (659 articles) } \\
\text { Xenopus (126 articles) }\end{array}$ \\
\hline
\end{tabular}

